\title{
Uma Avaliação da Política Macroeconômica do Governo Lula I
}

José Luís Oreiro*

Lucas L. Dezordi*

Terminado o primeiro mandato do Presidente Luiz Inácio Lula da Silva é chegado o momento de se fazer uma avaliação da gestão da política macroeconômica durante o seu governo. Como é bem sabida, a condução da política macroeconômica foi um dos maiores focos de atenção durante o primeiro mandato. Por um lado, vários membros do PT e intelectuais de esquerda pressionaram o governo no sentido de mudar o modelo macroeconômico herdado da administração Fernando Henrique Cardoso, o qual se baseava no tripé superávit primário-metas de inflação-câmbio flutuante. Por outro lado, membros da equipe econômica do governo - tanto no Banco Central como, até pouco tempo atrás, do próprio Ministério da Fazenda - e economistas ligados direta ou indiretamente ao mercado financeiro pressionavam o governo no sentido de completar as reformas de caráter liberalortodoxo iniciadas durante o governo FHC, defendendo a independência operacional do Banco Central do Brasil e a plena-conversibilidade da conta de capitais do balanço de pagamentos, destruindo assim os últimos resquícios de controles administrativos ao fluxo de capitais externos.

Passados quatro anos, o balanço final de forças parece ser o seguinte. O modelo macroeconômico herdado de FHC II está consolidado e, ao que tudo indica, não há nenhuma discussão séria dentro do governo no sentido de substituir o referido modelo por alguma alternativa mais "heterodoxa". As discussões em curso atualmente são mais no sentido de flexibilizar o modelo existente, do que pensar alternativas ao mesmo. No entanto, o aprofundamento do modelo macroeconômico existente por intermédio da concessão formal de autonomia operacional do Banco Central e da plena-conversibilidade da conta de capitais do balanço de pagamentos parece também ter sido deixada de lado ${ }^{4}$.

\footnotetext{
* Doutor em Economia (IE/UFRJ), Professor Adjunto do Departamento de Economia da UFPR, Diretor do CEPEC/UFPR e Pesquisador do CNPq. E-mail: joreiro@ufpr.br. Página pessoal: www.joseluisoreiro.ecn.br.

** Aluno do Programa de Doutorado em Desenvolvimento Econômico da UFPR e Professor da FAE Business School. E-mail: ldezordi@,fae.edu e lucasdezordi@uol.com.br.

4 A proposta de plena-conversibilidade da conta de capitais do balanço de pagamentos foi feita originalmente por Pérsio Arida em dois artigos publicados na Revista de Economia Política no ano de 2003. Essa proposta foi duramente criticada por diversos economistas brasileiros ao longo dos anos de 2004 e 2005 . Alguns exemplos de crítica a proposta de Arida são Oreiro, Paula e Silva (2004), Ferrari Filho et alli (2005) e Ono et alli (2005).
} 
Nesse contexto, o presente artigo tem por objetivo fazer uma avaliação do modelo macroeconômico adotado no primeiro ano de governo Lula destacando os principais resultados do tripé superávit primário- metas de inflação- câmbio flutuante.

\section{Política Monetária}

Ao contrário do que muitos analistas previam sobre a condução da política monetária e, até mesmo, do discurso oficial de campanha do candidato do PT, a política monetária ficou mantida sob o arcabouço operacional do regime de metas de inflação. A troca do então presidente do Banco Central do Brasil (BCB), Armínio Fraga Neto, pelo recém eleito deputado federal pelo PSDB e ex-presidente do Bank of Boston Henrique Meirelles foi bem recebida pelo mercado financeiro. $\mathrm{O}$ início do mandato do presidente Lula necessitava de uma grande cautela e, sobretudo, responsabilidade na condução da política monetária, pois no ano de 2002 a inflação tinha acumulado uma variação de 12,53\% no IPCA e 25,30\% no IGP-M. O gráfico 1 descreve o comportamento da inflação anualizada medida pelo IPCA, índice oficial do regime de metas.

No primeiro ano de governo a meta oficial de inflação a ser seguida pelo BCB, de acordo com a Resolução 2.972, era de 4\% com intervalo +/- de 2,5\%. Contudo, devido às turbulências ocorridas no mercado cambial em 2002 e a aceleração inflacionária observada neste ano, o BCB decidiu implementar uma meta provisória a ser perseguida de 8,5\% para 2003. Entretanto, a inflação em 2003 ficou em 9,30\%, isto é, acima da meta oficial e proposta. No primeiro semestre de 2004, como demonstrado no gráfico 1, a inflação convergiu rapidamente para a meta de 5,5\% ao ano e, o BCB reduziu rapidamente os juros que estavam em 26\% ao ano em 2003 para 15,75\% ao ano. O forte crescimento econômico brasileiro e mundial de 2004 pressionou novamente a inflação nacional, sendo que em 2005 o IPCA acumulado em doze meses chegou a 8,0\%, levando o BCB a subir a taxa de juros. A queda da inflação, como destacada no gráfico 1, foi rápida e consistente. O ano de 2005 registrou uma inflação de 5,69\% e em novembro de 2006 a inflação anualizada está em 3,02\%.

Uma característica importante do regime de metas de inflação adotado no primeiro mandato do governo Lula foi a rápida e consistente queda da taxa de inflação. Por exemplo, em janeiro de 2003 o IPCA acumulava em 12 meses uma alta de 14,47\% e em novembro de 2006, final de mandato, uma alta de apenas 3,02\%. Isto é: a inflação em quatro anos consecutivos caiu 11,45 p.p. 


\section{Gráfico 1. O Regime de Metas de Inflação no Governo Lula: 2003 a 2006*}

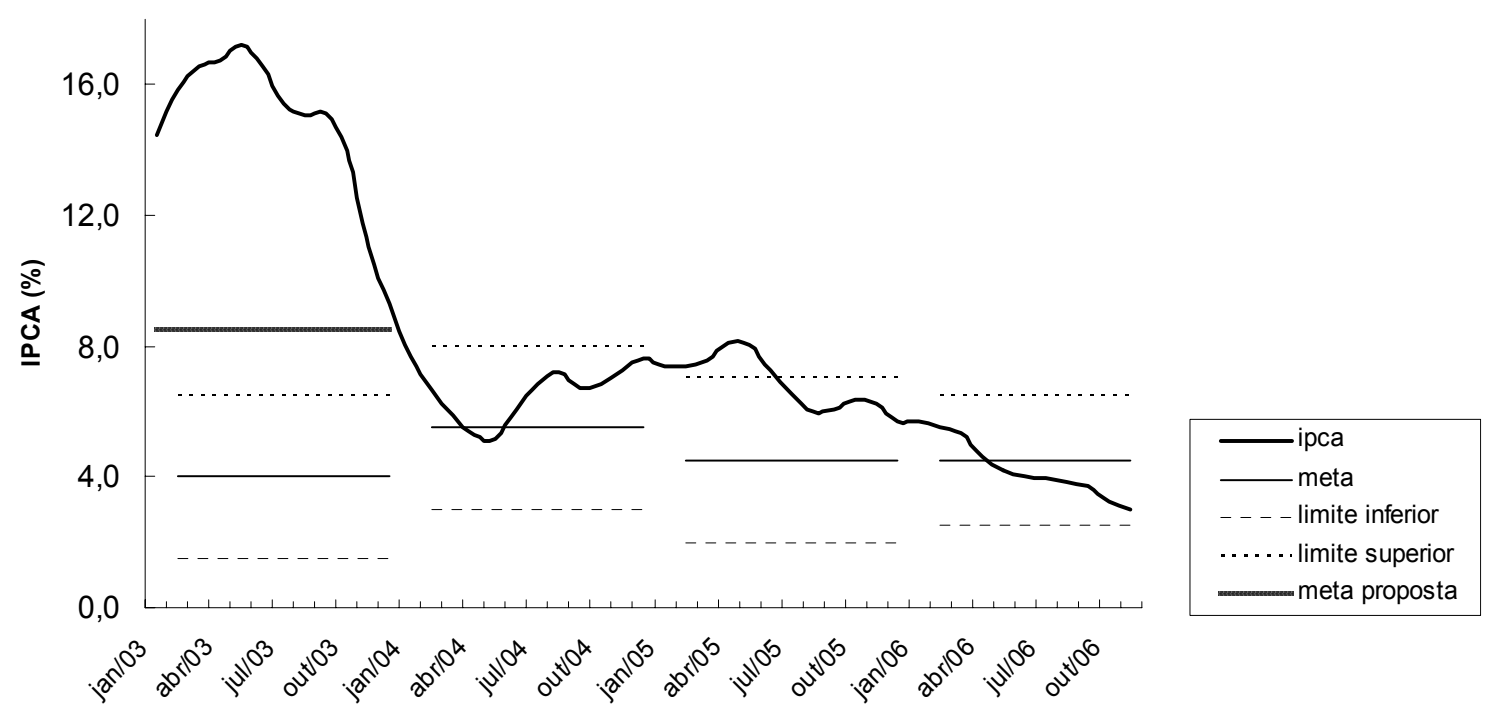

Fonte: IBGE e BCB. Boletim Economia \& Tecnologia. * Em 2006 até novembro.

O governo Lula iniciou seu governo praticando uma taxa de juro real de aproximadamente $9 \%$ ao ano. Com o processo inflacionário se intensificando em 2003 a taxa real de juros caiu para seu menor valor histórico: 5\% ao ano. No entanto, com a elevação rápida e consistente da taxa de juros nominal e a diminuição da inflação, a taxa de juros real subiu, em menos de quatro meses, para um valor acima de $9 \%$ ao ano, como destacado no gráfico 2. Um ponto importante a ser destacado está no fato que desde 2004 a taxa de juros real vem oscilando entre 9 a 11\% ao ano, sendo que em agosto de 2005 esta atingiu seu valor máximo de 12,95\% ao ano. A partir daí, a taxa de juros real vem caindo gradativamente. Atualmente, a economia brasileira vem operando com uma taxa real em torno de 10,3\% ao ano. 
Gráfico 2. Taxa de juros reais no governo Lula: 2003 A 2006*

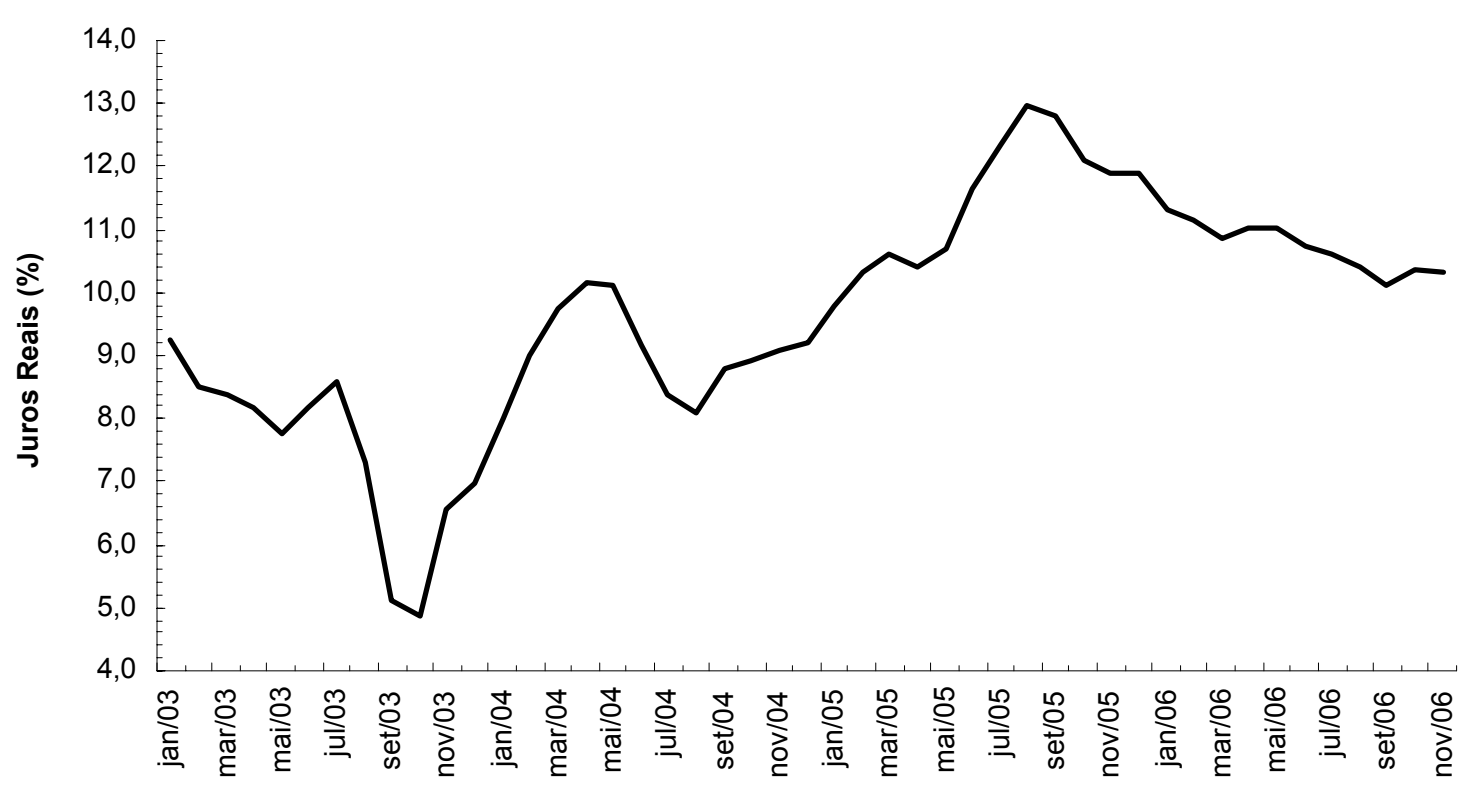

Fonte: IBGE e BCB. Boletim Economia \& Tecnologia. Cálculo dos autores. * Em 2006 até novembro.

\section{Política Fiscal}

A partir da crise financeira vivida pelo Brasil no segundo trimestre de 2002, o governo brasileiro reforçou as atuais políticas, formulou um conjunto de medidas estruturais e solicitou ao FMI um novo programa com o objetivo de garantir um ambiente de estabilidade para uma tranqüila transição governamental (no caso, o governo Lula).

Uma das medidas foi a elevação em $0,25 \%$ do PIB da meta de superávit primário do setor público consolidado, para 3,75\% do PIB em 2002/03. O Congresso, com o intuito de reforçar o ajuste fiscal, aprovou a prorrogação da Contribuição Provisória sobre Movimentação Financeira (CPMF), cujo prazo de vigência se encerraria em 17 de junho de 2002.

Entretanto, o governo eleito anunciou uma meta de superávit primário para o setor público não financeiro consolidado de $4,25 \%$ do PIB para 2003. Esta meta tinha como objetivo garantir uma dinâmica favorável da relação dívida/PIB, refletindo a realidade fiscal do país e a preservação do gasto social, visto o aumento da taxa real de juros para combater o processo inflacionário no início do primeiro governo.

A meta de 4,25\% do PIB permaneceu até setembro de 2004, quando esta aumentou para 4,5\% nos últimos 3 meses do ano. Já em janeiro de 2005 até outubro de 2006 a meta oficial do superávit primário voltou para o patamar de 4,25\% do PIB. O gráfico 3 destaca o 
comportamento do superávit primário do setor público consolidado desde 2002, um ano antes do governo Lula, até outubro de 2006. O período de maior aperto fiscal ocorreu em 2005, sendo que o superávit passou dos 5,0\% do PIB. Em 2006, este caiu para um valor próximo da meta e atualmente permanece flutuando um pouco acima desta.

\section{Gráfico 3. Resultado Primário do Setor Público Consolidado: 2002 a 2006*}

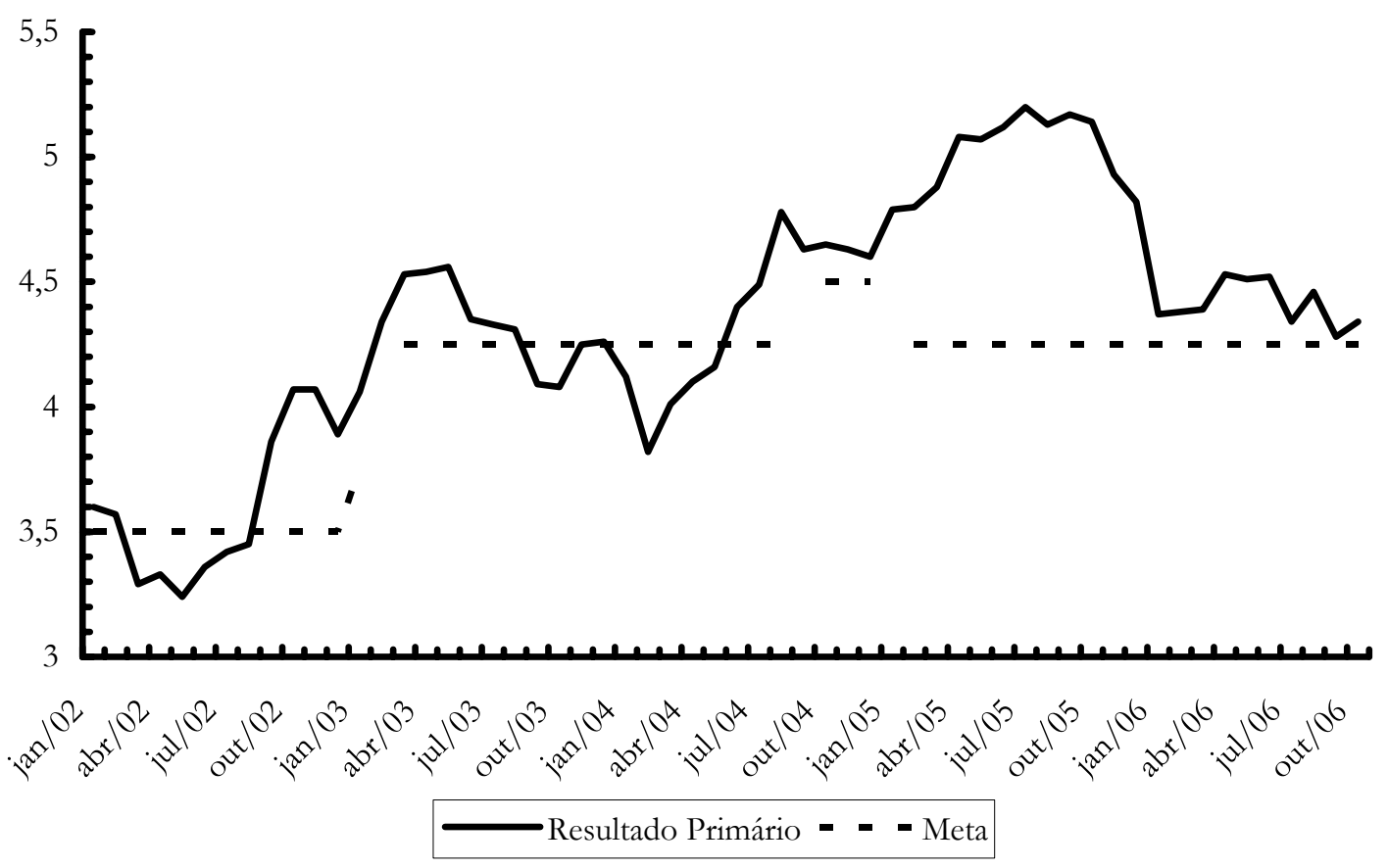

Fonte: MF/STN. Boletim Economia \& Tecnologia. * Em 2006 até outubro.

O primeiro ano do governo Lula foi marcado pela elevação do superávit primário em relação ao PIB. O gráfico 4 demonstra que em 2002 o superávit primário em relação ao PIB fechou em 3,89\%, em 2003 subiu para 4,26\%, em 2005 atingiu seu maior valor de 4,82\% e em 2006 manteve-se forte, em 4,34\% do PIB. 
Gráfico 4. Resultado Primário anual em \% do PIB: 2002 a 2006*

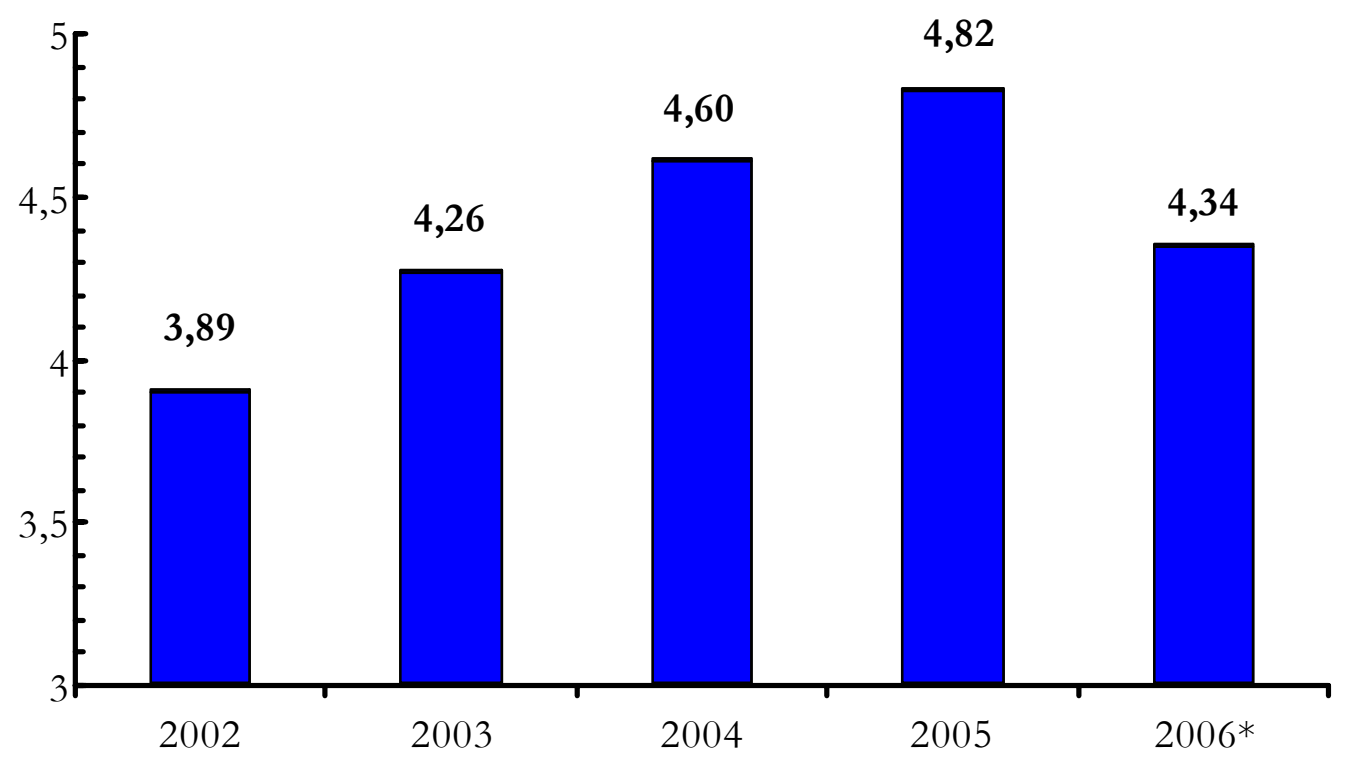

Fonte: MF/STN. Boletim Economia \& Tecnologia. * Em 2006 até outubro.

A importância da manutenção do superávit primário para a economia brasileira está na necessidade de se estabilizar e até mesmo reduzir a dívida líquida do setor público em relação ao PIB. O gráfico 5 ilustra que esta relação aumentou no primeiro ano de governo, chegando a um valor de 57,2\% do PIB. Contudo, com o crescimento econômico de 2004 e a queda do juro real, a dívida caiu para um valor de 51,7\% do PIB. Esta razão se manteve em 2005 e caiu para 49,5\% até outubro de 2006.

Mantendo a dívida neste patamar e considerando uma taxa de juros real de 10,32\% ao ano, crescimento econômico de 3,5\% e superávit primário de 4,34\% em 2007, projeta-se uma relação dívida/PIB decrescente na ordem de 48,54\% do PIB em 2007.

Um ponto importante a ser destacado é que se mantendo o cenário econômico atual, descrito anteriormente, a dívida líquida em proporção do PIB tende a cair. Caso a taxa de juros real venha a cair mais, não gerando pressão inflacionária e, como conseqüência, destravando o crescimento econômico brasileiro, a dinâmica da dívida, com certeza, ficará mais confortável. 


\section{Gráfico 5. Dívida Líquida do Setor Público / PIB: 2002 a 2007**}

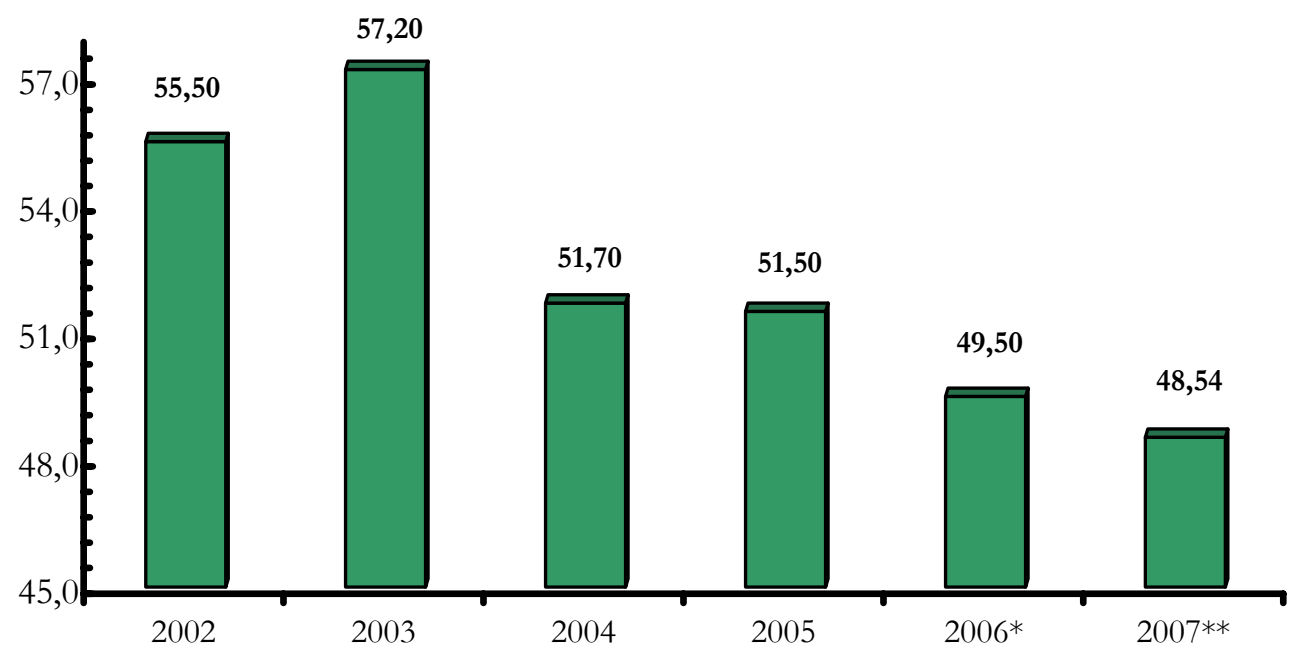

Fonte: MF/STN. Boletim Economia \& Tecnologia. * Em 2006 até outubro. ** Projeções dos autores.

Entretanto, a manutenção do cenário atual depende de importantes ajustes fiscais. Ou seja, é fundamental analisar como o superávit primário vem sendo obtido. Os gráficos 6 e 7 destacam uma realidade não muito animadora para o governo Lula na área fiscal. As despesas correntes do governo em relação ao PIB passaram de 16,9\% em 2002 para 18,2\% em setembro de 2006 e as receitas administradas ${ }^{5}$ em relação ao PIB subiram de 16,3\% para $17,3 \%$ no mesmo período.

Neste sentido, fica claro que o ajuste fiscal está sendo obtido com uma combinação 'amarga' de crescimento dos gastos correntes do governo e aumento dos tributos que afetam diretamente o desempenho da oferta e demanda agregada da economia.

O gráfico 7 destaca que as despesas obrigatórias em relação ao PIB cresceram de 13,9\% em 2002 para 15,6\% em setembro de 2006 enquanto que as despesas discricionárias permaneceram estáveis em 4,0\% do PIB, no mesmo período. Os gastos obrigatórios representam as despesas com Pessoal e Encargos Sociais; Abono e Seguro Desemprego; Subsídios; Crédito Extraordinário, entre outros. Já as despesas discricionárias representam os gastos governamentais nos Ministérios do Poder Executivo, Poder Legislativo, Judiciário e MPU.

${ }^{5}$ As receitas administradas apresentam as seguintes rubricas: Imposto Importação; IPI; Imposto de Renda; IOF; COFINS; CPMF; CIDE - Combustível, entre outros. Para maiores detalhes, acessar: http://www.planejamento.gov.br/orcamento/conteudo/relatorio avaliacao/avaliacao rec desp uniao.htm/ 
Como estes gastos permaneceram congelados no governo Lula, o investimento público em relação ao PIB também não foi elevado, representando atualmente cerca de $0,3 \%$ do PIB. Pode-se argumentar que a qualidade do ajuste fiscal brasileiro não é boa. A manutenção do superávit primário é fundamental, entretanto, uma nova configuração fiscal deve ser desenhada, com redução de gastos correntes e diminuição dos impostos para ampliar os gastos públicos em investimentos conforme Programa Piloto de Investimentos.

Gráfico 6. Crescimento das Despesas Correntes do Governo e das Receitas Administradas em \% do PIB: 2002 a 2006*



Fonte: MPOG/SOF. Boletim Economia \& Tecnologia. * Em 2006 até setembro.

Gráfico 7. Despesas Obrigatórias e Discricionárias em \% do PIB: 2002 A 2006*

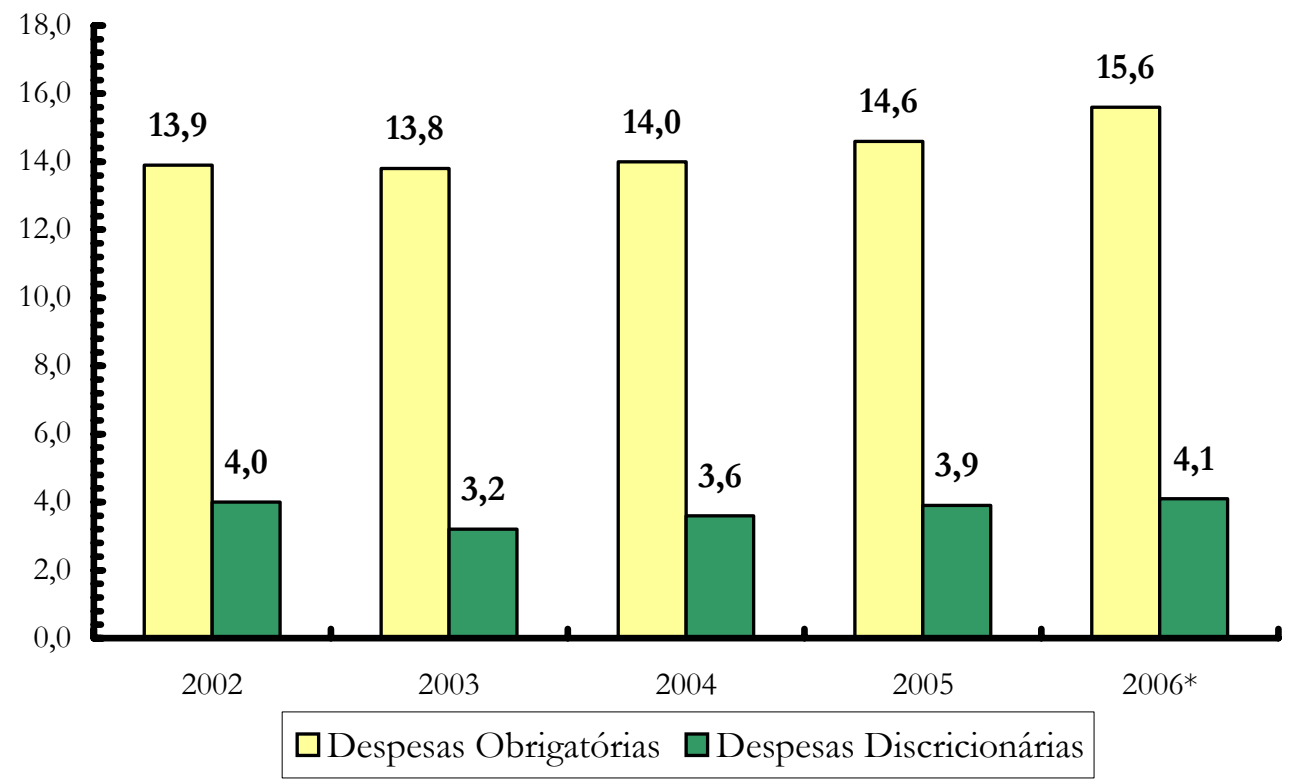

Fonte: MPOG/SOF. Boletim Economia \& Tecnologia. * Em 2006 até setembro. 


\section{Política Cambial}

O desempenho externo do primeiro mandato do governo Lula foi amplamente beneficiado pelas condições de crescimento mundial e pela elevada liquidez internacional. Os principais resultados foram quatro anos de superávit na conta transações correntes do balanço de pagamento, aumento das reservas internacionais, crescimento do fluxo de comércio e diminuição da dívida externa.

O gráfico 8 ilustra a vitalidade do setor externo brasileiro. No início do governo Lula I, as exportações acumuladas em 12 meses representavam cerca de US\$ 60 bilhões e em outubro de 2006 esse valor ultrapassou o valor de US\$ 135 bilhões. As importações anualizadas também cresceram passando de US $\$ 47$ bilhões para US\$ 88 bilhões no mesmo período. Com isso, o saldo da balança comercial saltou de US\$ 14 bilhões para um valor acima dos US\$ 46 bilhões, no mesmo período.

\section{Gráfico 8. Desempenho da Balança Comercial anualizada: 2002 A 2006*}

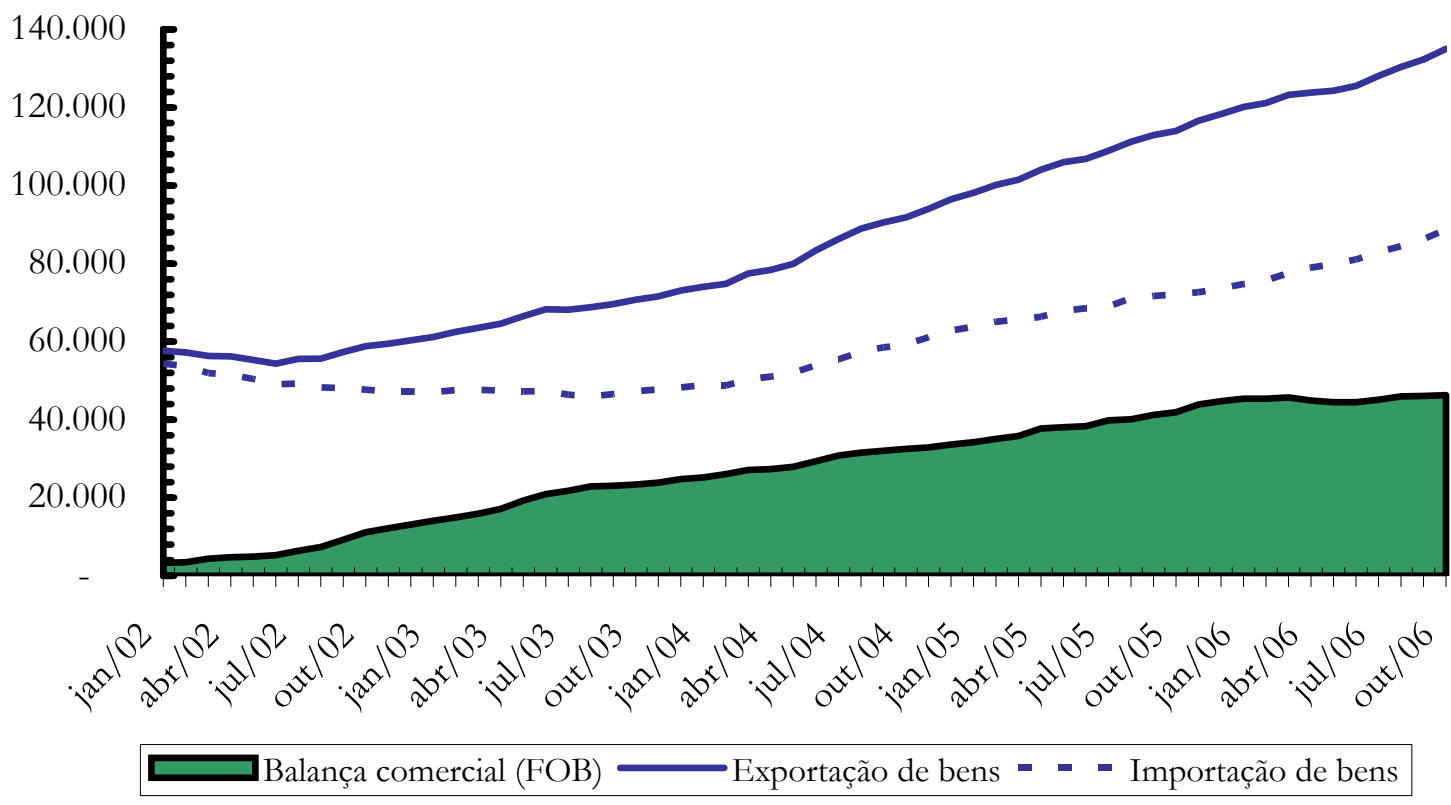

Fonte: BCB-DEPEC. Boletim Economia \& Tecnologia. * Em 2006 até outubro.

Após oito anos consecutivos de déficit em transações correntes do balanço de pagamentos, o Brasil em 2003, com o forte crescimento das exportações começa a reverter esse quadro, apresentando um superávit de 0,82\% do PIB em 2003, 1,94\% em 2004, 1,76\% em 2005 e 1,54\% até outubro de 2006. 
Gráfico 9. Saldo em Transações Correntes/PIB (\%): 2002 A 2006*

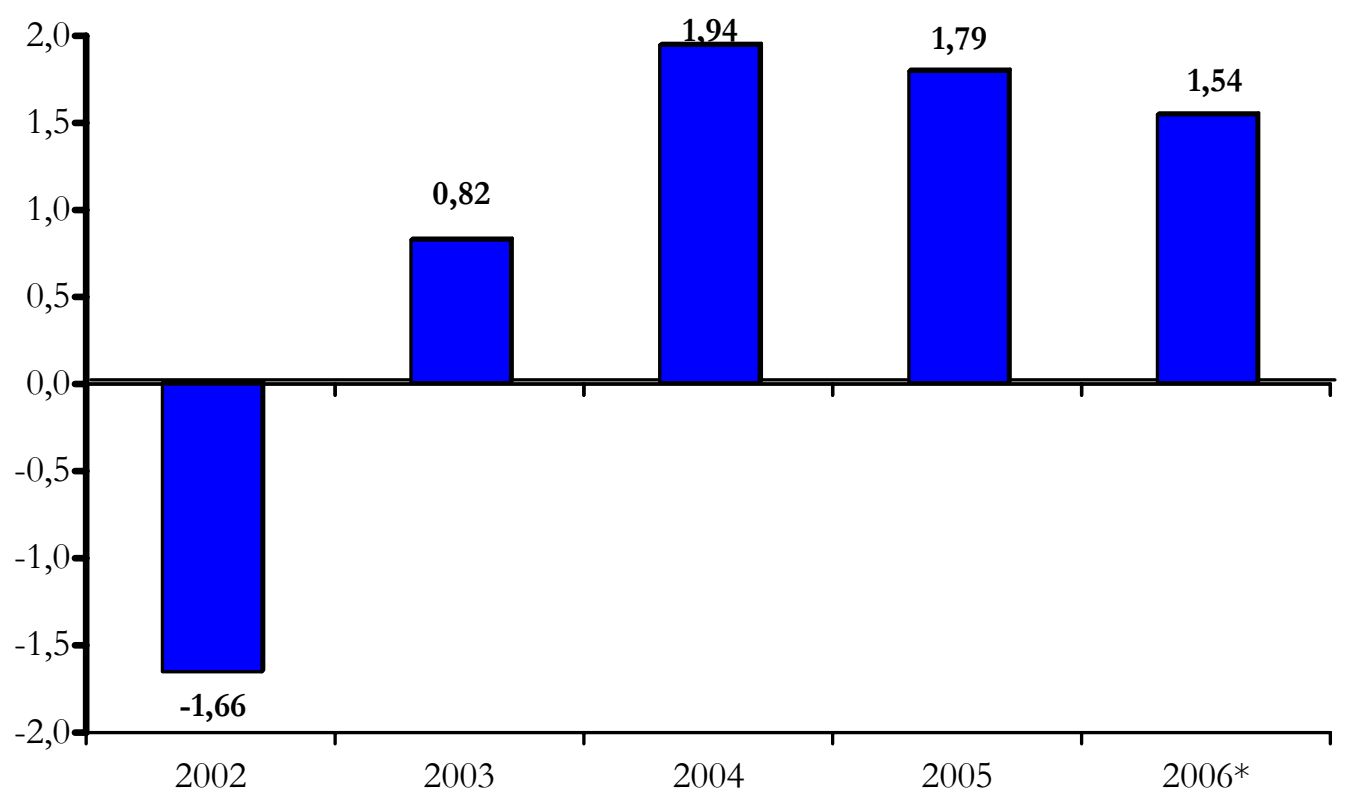

Fonte: BCB-DEPEC. Boletim Economia \& Tecnologia. * Em 2006 até outubro.

O gráfico 10 destaca o desempenho dos principais indicadores de vulnerabilidade externa. Nos últimos quatro anos, todos estes indicadores melhoraram. A relação dívida externa líquida/exportações que era de 2,8 (eram necessários 2 anos de 9 meses de exportações para pagar a dívida líquida), em 2002 caiu significativamente para 0,6 (seis meses de exportações pagam a dívida) em 2006.

A razão reservas internacionais sobre o serviço da dívida aumentou ${ }^{6}$, mostrando que o país apresenta mais reservas para pagar o serviço da dívida (juros da dívida externa), isto é, o país se tornou menos vulnerável no front externo. Essa razão é muito utilizada em países que adotam como referência um regime de câmbio fixo, e neste caso as reservas internacionais têm um papel mais relevante nas contas externas.

Já o último indicador, serviço da dívida sobre exportações, é mais importante para um país com regime de câmbio flutuante. Ele indica em termos percentuais o volume de serviços da dívida sobre o volume de exportações e, quanto menor for esse valor menos vulnerável é o país. Em 2002, com o crescimento das exportações, o Brasil apresentava uma relação de 84,9\%, em 2004 esse indicador caiu para 53,7\% e no segundo trimestre de 2006 está em $61,2 \%$.

${ }^{6}$ Esse indicador mostra que se o país, em um determinado período, não apresentar nenhuma receita de exportações, isto é, entrada de moeda estrangeira, este ainda tem caixa para pagar os juros da dívida externa. Quanto maior o volume de reservas internacionais e menor o volume de serviço da dívida, maior é o indicador e menos vulnerável é o país. 
Gráfico 10. Principais indicadores de vulnerabilidade externa: 2002 A 2006*

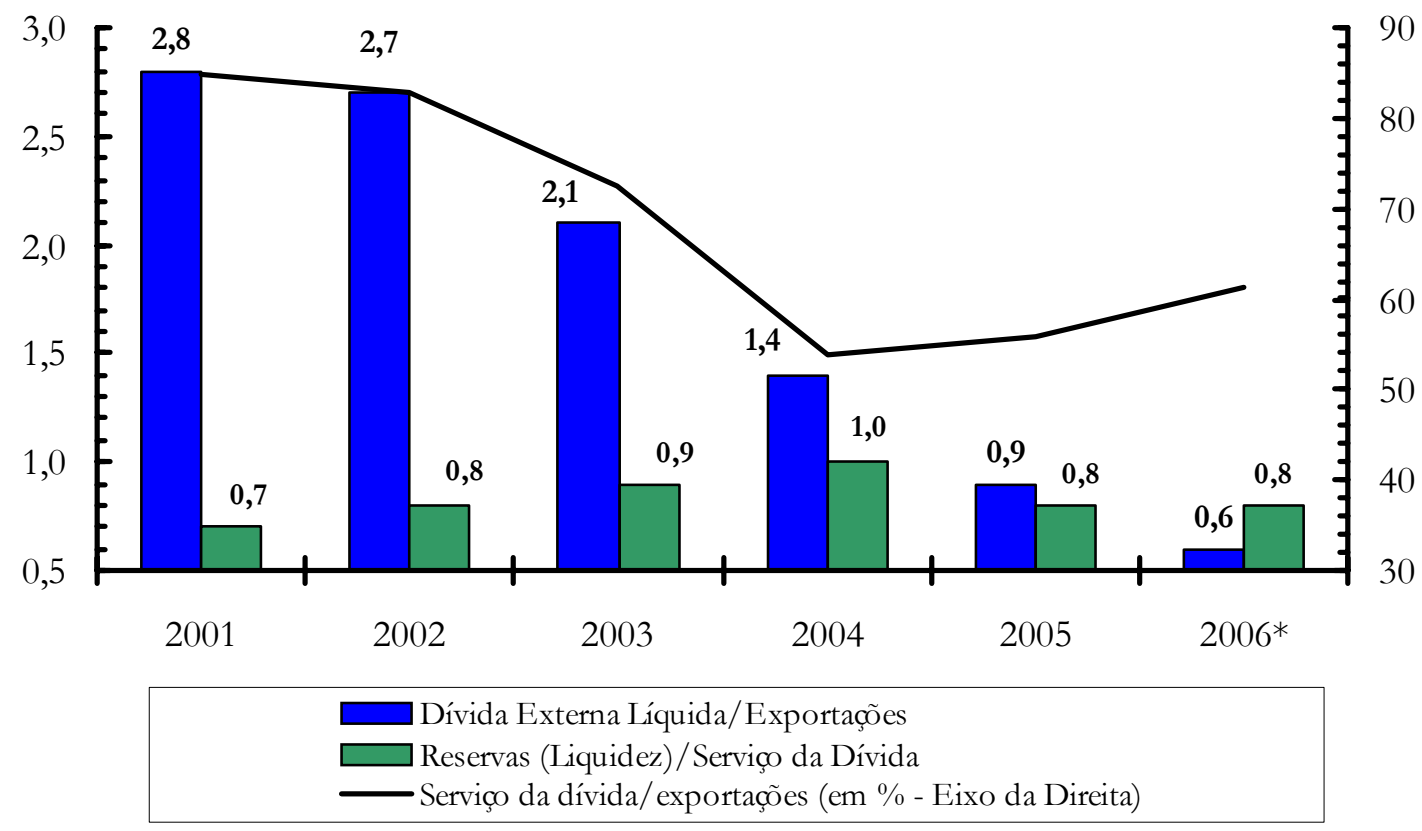

Fonte: BCB-DEPEC. Boletim Economia \& Tecnologia. * Segundo trimestre de 2006.

Entretanto, o forte desempenho do setor externo e a política de juros elevados do Banco Central vêm fazendo com que o Brasil apresente um forte fluxo de entrada de moeda estrangeira (dólar norte-americano), gerando com isso uma forte apreciação nominal e real da taxa de câmbio. O gráfico 11 destaca uma situação preocupante no cenário externo nacional: o câmbio efetivo está muito apreciado. Neste sentido, a situação externa confortável pode dar lugar a uma piora nos indicadores externos, principalmente pelo saldo em transações correntes do balanço de pagamentos.

No início do governo Lula I a taxa de câmbio real apresentava uma forte depreciação, ocasionando em um ganho de competitividade externa. Entretanto, esse indicador durante o seu governo vem apresentando uma forte apreciação e perda de competitividade. O gráfico, abaixo, destaca que o câmbio efetivo atual apresenta o mesmo valor de junho de 1994, período no qual o país adotava uma âncora cambial para conter a hiperinflação. 


\section{Gráfico 11. Taxa de câmbio efetiva Real (IPCA): Jan/2002 A Out/2006}


\section{Conclusão}

Ao longo deste artigo apresentamos os principais resultados da política macroeconômica adotada durante o primeiro mandato do governo Lula. Como aspectos positivos podemos destacar: a queda da taxa de inflação para um patamar próximo de $4 \%$ a.a; estabilização/redução da dívida pública como proporção do PIB, afastando o risco de default por parte do governo brasileiro; e uma redução significativa da fragilidade externa da economia brasileira, a partir da obtenção de superávits na conta de transações correntes do balanço de pagamentos, aumento das reservas internacionais e forte aumento das exportações.

No entanto, o modelo macroeconômico brasileiro possui ainda uma série de fragilidades. Em primeiro lugar, o "problema dos juros" no Brasil não foi ainda equacionado. A taxa real de juros de curto-prazo continua acima de $9 \%$ a.a, um valor que não é só extremamente elevado do ponto de vista internacional como, principalmente, impede a aceleração do crescimento da economia brasileira na medida em que a mesma se constitui no custo de oportunidade dos investimentos do setor produtivo.

Em segundo lugar, a qualidade do ajuste fiscal brasileiro é muito ruim: o superávit primário, embora suficiente para estabilizar/reduzir a dívida pública, tem sido gerado por uma combinação perversa de aumento da carga tributária, aumento dos gastos de consumo do 
governo e redução do investimento público em obras de infra-estrutura; o que certamente tem efeitos deletérios sobre o crescimento de longo-prazo da economia brasileira.

Por fim, a combinação entre juros elevados, aumento do preço das commodities internacionais e baixo crescimento da economia tem gerado um elevado fluxo de entrada de divisas - tanto pela conta comercial como pela conta financeira - o qual resultou numa forte apreciação da taxa real de câmbio. Essa apreciação do câmbio, embora ainda não esteja comprometendo o saldo da balança comercial, está afetando adversamente os setores da indústria brasileira que são mais intensivos em trabalho. Dessa forma, a capacidade de crescimento da economia brasileira no longo-prazo pode ser comprometida uma vez que se reduzem os efeitos multiplicadores - via massa salarial - sobre o PIB de um aumento exógeno da demanda agregada. 
